\title{
Correlations between design of the dental implants and their survival rate
}

\author{
Corelații între designul implanturilor dentare și rata lor de supraviețuire
}

\author{
Alexandru Daniel Referendaru ${ }^{1,2}$, Costin Coman ${ }^{3}$, Raluca Monica Comăneanu ${ }^{3}$, Anca Iuliana Popescu ${ }^{3}$, \\ Horia Mihail Barbu ${ }^{2,3}$ \\ ${ }^{1}$ Şcoala Doctorală - Domeniul Medicină Dentară, IOSUD „Titu Maiorescu“, Bucureşti, România \\ ${ }^{2}$ Clinica de Reabilitare Orală „Prof. Dr. Barbu“,Bucureşti, România \\ ${ }^{3}$ Facultatea de Medicină Dentară, Universitatea „Titu Maiorescu“, Bucureşti, România
}

\begin{abstract}
Objectives. The study aimed to establish correlations between implant geometry, bone density and survival rate of implant therapy.

Material and method. The study material consisted of medical documents (clinical observation and treatment sheets, which included both the results of recommended laboratory tests, photographs and imaging investigations performed pre / intra / postoperatively) of patients who were addressed between October 1st, 2014 and October 1st, 2018 to the Oral Rehabilitation Clinic „Prof. Dr. Barbu“. The study included patients wearing mobilizable prostheses, with advanced periodontal diseases that required tooth extraction, patients who accepted dental implants as a treatment solution and presented at all scheduled sessions, including long-term post-therapeutic dispensary of at least 1 year. Statistical processing was performed with Microsoft Excel 2016.

Results. The study group included 73 patients of both sexes ( 28 men and 45 women), old carriers of mobilizable prostheses, with severe periodontal diseases, which required dental extractions. 618 implants were inserted in the study group in order to prosthetic the edentulous gaps.

Discussions. The study highlighted the high interest of females in the application of modern dental therapies. At the age group, the 50-59 age group was best represented, closely followed by the 40-49 age group. Most implants were inserted at the upper arch, at a right angle and were conical.

Conclusions. Due to the lower bone density in the upper arch, $81.4 \%$ of failures occurred in the group studied in the jaw. Implants with small steps between turns have a better prognosis compared to implants with large steps between turns. From the point of view of the type of implant, the cylindrical-conical ones had the best prognosis, and the zygomatic ones registered the weakest prognosis. Bone additions were correlated with a higher failure rate ( $55.81 \%$ of cases). Implants inserted at $10^{\circ}$ had the best survival rate, and those inserted at $35^{\circ}$ and $55^{\circ}$ had the lowest survival rate.
\end{abstract}

Keywords: dental implant, small step between turns, large step between turns, insertion angle

\section{REZUMAT}

Obiective. Studiul a avut drept scop stabilirea unor corelații între geometria implanturilor, densitatea osoasă și rata de supraviețuire a terapiei implantare.

Material şi metodă. Materialul de studiu a fost alcătuit din documentele medicale (foile de observație clinică și tratament, ce au inclus atât rezultatele analizelor de laborator recomandate, cât și fotografiile și investigațiile imagistice efectuate pre, intra, postoperator) ale pacienților care s-au adresat în perioada 1 octombrie 2014 -1 octombrie 2018 Clinicii de Reabilitare Orală „Prof. Dr. Barbu“. În studiu au fost incluși pacienții vechi purtători de proteze mobilizabile, cu afecțiuni parodontale avansate ce impuneau extracția dentară, pacienți care au acceptat ca soluție de tratament protezarea pe implanturi si s-au prezentat la toate sedintele planificate, inclusiv la dispensarizarea postterapeutică pe o durată de minimum 1 an. Prelucrarea statistică s-a efectuat cu Microsoft Excel 2016.

Rezultate. Lotul de studiu a cuprins 73 de pacienți de ambele sexe (28 bărbați și 45 femei), vechi purtători de proteze mobilizabile, cu afecțiuni grave parodontale, care au impus efectuarea extracțiilor dentare. La lotul de studiu s-au inserat 618 implanturi în vederea protezării breșelor edentate.

Discuţii. Studiul a subliniat interesul ridicat al persoanelor de sex feminin faţă de aplicarea terapiilor stomatologice moderne. La nivelul grupelor de vârstă, cel mai bine a fost reprezentată grupa 50-59 ani, urmată îndeaproape de grupa 40-49 ani. Majoritatea implanturilor au fost inserate la arcada superioară, sub un unghi drept și au fost de tip conic.

Concluzii. Ca urmare a densității osoase mai reduse de la nivelul arcadei superioare, 81,4\% dintre eșecuri s-au produs la lotul studiat la maxilar. Implanturile cu pas mic între spire au avut un prognostic mai bun în comparație cu 
implanturile cu pas mare între spire. Din punctul de vedere al tipului de implant, cele cilindro-conice au avut cel mai bun prognostic, iar cele zigomatice au înregistrat cel mai slab prognostic. Adițiile osoase au fost corelate cu o rată mai mare de eșec (55,81\% dintre cazuri). Implanturile inserate la $10^{\circ}$ au avut cea mai bună rată de supraviețuire, iar cele inserate la $35^{\circ}$ şi $55^{\circ}$ au aavut cea mai redusă rată de supraviețuire.

Cuvinte cheie: implant dentar, pas mic între spire, pas mare între spire, unghi de inserare

\section{INTRODUCERE}

Spre deosebire de restaurările protetice fixe convenționale, reabilitările cu sprijin implantar prezintă avantaje [1] legate de rata crescută de supraviețuire, menținerea volumului crestei edentate și menajarea vitalităţii dinţilor limitanţi breșei edentate.

Pacientul care va beneficia de terapie implantoprotetică va fi evaluat preoperator din punct de vedere medical [2,3] și imagistic [1], pentru a adapta terapia la terenul pacientului. Se consideră că terapia a avut eșec dacă: mobilitatea orizontală a implantului este peste $0,5 \mathrm{~mm}$; se remarcă o pierdere osoasă rapidă, progresivă; pacientul reclamă durere la percuţie; este prezent periimplantar un exsudat necontrolat; periimplantar, descoperim imagistic o radiotransparenţă generalizată; pierderea osoasă din jurul implantului depășește jumătate din înălţimea implantului; implantul este inserat într-o poziţie nefavorabilă sprijinului protetic [2].

\section{MATERIAL ŞI METODĂ}

Materialul de studiu a fost alcătuit din documentele medicale (foile de observație clinică și tratament, ce au inclus atât rezultatele analizelor de laborator recomandate, cât și fotografiile și investigațiile imagistice efectuate pre, intra, postoperator) ale pacienților care s-au adresat în perioada 1 octombrie 2014 - 1 octombrie 2018 Clinicii de Reabilitare Orală „Prof. Dr. Barbu“.

În studiu au fost incluși pacienții vechi purtători de proteze mobilizabile, cu afecțiuni parodontale avansate ce impuneau extracția dentară, pacienți care au acceptat ca soluţie de tratament protezarea pe implanturi şi s-au prezentat la toate ședințele planificate, inclusiv la dispensarizarea postterapeutică pe o durată de minimum 1 an.

Studiul retrospectiv desfăşurat nu a necesitat din partea pacienților un consimțământ suplimentar față de acordul scris al acestora, cuprins în documentele clinicii, ce permite utilizarea informațiilor lor medicale în scopuri științifice, respectând protecția datelor cu caracter personal.
S-a creat o bază de date în care au fost consemnate toate datele colectate (sexul, vârsta, numărul implanturilor inserate la fiecare pacient, localizarea situsurilor implantare, eventualele eşecuri înregistrate, tipul de adiţie osoasă efectuată, forma implanturilor, caracteristicile spirelor implanturilor, tipul implanturilor - standard, pterigoidian, zigomatic, tipul încărcării efectuate - imediată sau tardivă). Prelucrarea statistică s-a efectuat cu Microsoft Excel 2016.

Studiul a avut drept scop stabilirea unor corelații între geometria implanturilor, densitatea osoasă și rata de supraviețuire a terapiei implantare.

\section{REZULTATE}

Lotul de studiu a cuprins 73 de pacienți de ambele sexe (28 bărbați și 45 femei), vechi purtători de proteze mobilizabile, cu afecțiuni grave parodontale, care au impus efectuarea extracțiilor dentare.

Frecvența pacienților pe grupe de vârstă este ilustrată în figura 1.

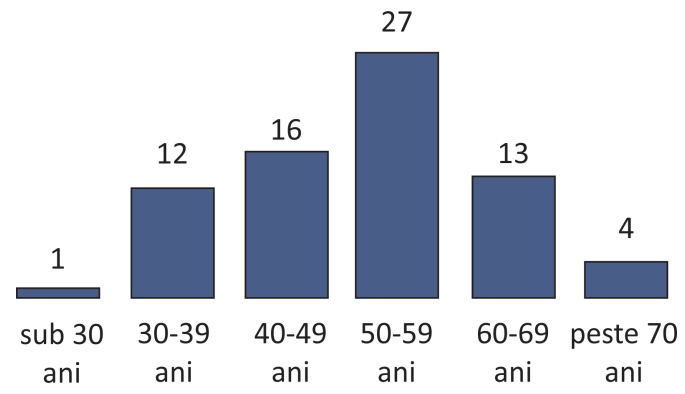

FIGURA 1. Frecvenţa pacienţilor pe grupe de vârstă

La lotul de studiu, s-au inserat 618 implanturi în vederea protezării breșelor edentate. Distribuția acestor implanturi în funcție de sexul pacienților, arcadele edentate și tipul de implant sunt prezentate în figura 2.

Distribuția eșecurilor apărute în cursul tratamentului este ilustrată în figura 3 .

Am analizat pentru lotul studiat corelaţia dintre unghiul de inserare și numărul de implanturi inserate, precum şi dintre unghiul de inserare şi eșecurile înregistrate (fig. 4). 


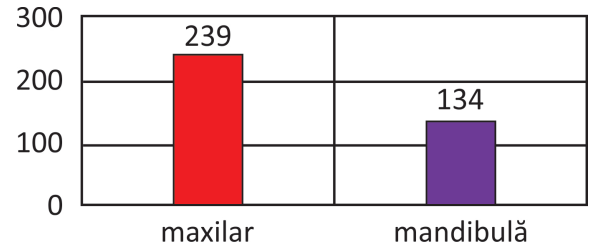

a

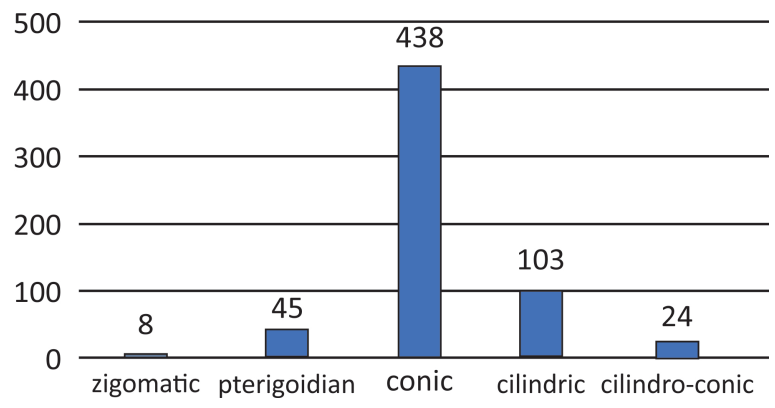

C

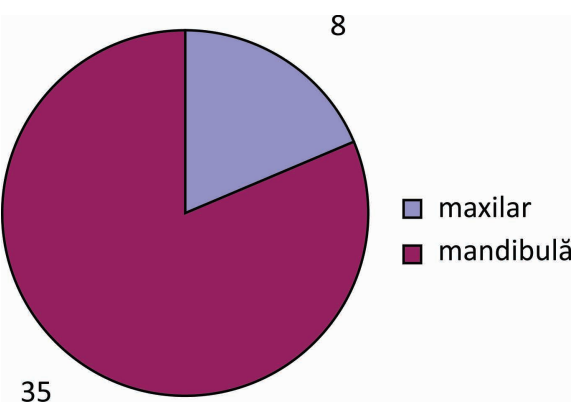

a

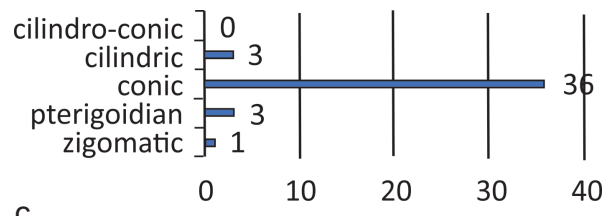

FIGURA 3. Distribuţia eşecurilor: a) pe arcade; b) în funcţie de tipul filetului implanturilor; c) în funcţie de tipul de implant, d) în funcţie de tipul de adiţie efectuat

Clasificarea lotului studiat în funcție de tipul de încărcare este ilustrată în figura 5.

\section{DISCUŢII}

Studiul nostru a subliniat interesul ridicat al persoanelor de sex feminin faţă de aplicarea terapiilor stomatologice moderne, lotul fiind compus, similar altor studii recente [4-9], preponderent din
FIGURA 2. Distribuţia implanturilor în funcţie de: a) arcadele edentate ale pacientelor; b) arcadele edentate ale pacienţilor; c) tipul de implant utilizat

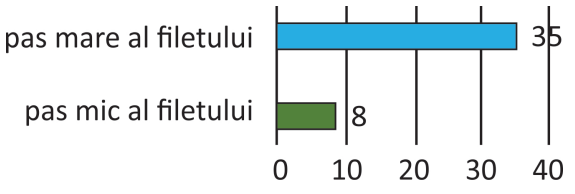

b

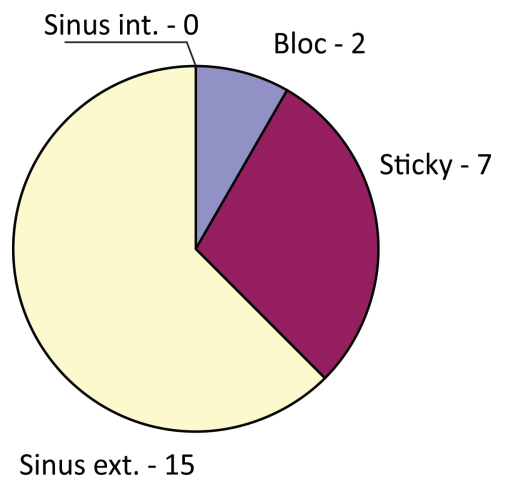

Sinus ext. - 15 

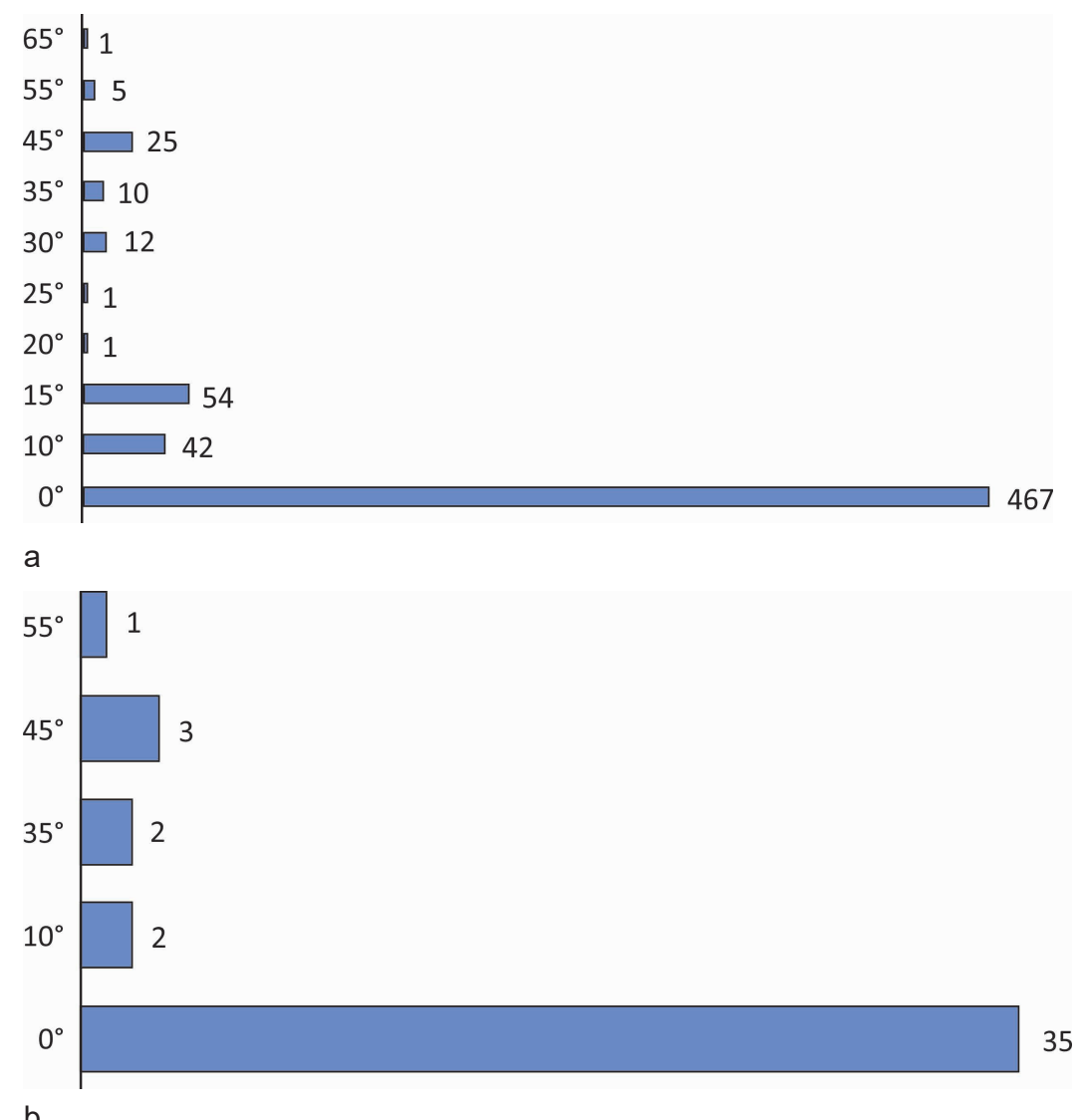

b

FIGURA 4. Corelaţii între unghi de inserare şi: a) numărul de implanturi inserate; b) eşecuri înregistrate

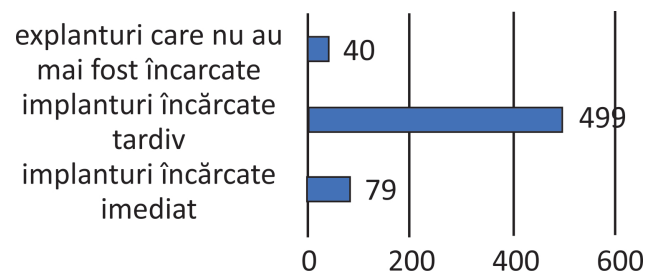

FIGURA 5. Clasificarea lotului de studiu după momentul încărcării

Tipurile de implanturi $[1,11,12]$ utilizate pentru reabilitarea orală a pacienților din lotul analizat au fost diferite, ca urmare a particularităţilor clinice individuale. La lotul studiat, implanturile cu pasul mic al spirelor au avut un prognostic mai bun (doar $18,6 \%$ din totalul cazurilor înregistrate de eşec).

La lotul analizat, au fost inserate majoritar (70,87\% din total) implanturi conice. Procentual, majoritatea eşecurilor s-au produs în cazul implanturilor zigomatice ( 1 eşec din 8 implanturi inserate, ceea ce reprezintă $12,5 \%$ din total). Pe locul secund, s-au situat implanturile conice (36 eşecuri din 438 implanturi, adică $8,22 \%$ din total). Pe locul $3 \mathrm{~s}$-au situat implanturile pterigoidiene $(6,67 \%$ din total eșecuri), iar pe locul 4 implanturile cilindrice $(2,91 \%$ rata de eşec). Implanturile cilindro-conice inserate la lotul studiat au avut zero rata de eşec.

O parte dintre pacienții lotului au necesitat augmentarea osoasă, așa cum consemnează și alte studii [13-16]. La lotul studiat, elevarea sinusului maxilar prin abord extern a fost cel mai mult corelată cu eșecul.

$75,57 \%$ dintre implanturi au fost inserate drept la lotul studiat, iar restul au fost inserate sub unghiuri între $10^{\circ}$ şi $65^{\circ}[17,18]$. Cea mai scăzută rată de eşec $(4,76 \%)$ la lotul studiat s-a înregistrat la implanturile înclinate cu $10^{\circ}$. 


\section{CONCLUZII}

Ca urmare a densității osoase mai reduse de la nivelul arcadei superioare, $81,4 \%$ dintre eșecuri s-au produs la lotul studiat la maxilar. Implanturile cu pas mic între spire au avut un prognostic mai bun în comparație cu implanturile cu pas mare între spire. Din punctul de vedere al tipului de implant, cele cilindro-conice au avut cel mai bun prognostic, iar cele zigomatice au înregistrat cel mai

\section{BIBLIOGRAFIE}

1. Gupta R, Weber KK. Dental Implants. In: StatPearls. Treasure Island (FL): StatPearls Publishing; 2020.

2. Diz P, Scully C, Sanz M. Dental implants in the medically compromised patient. J Dent. 2013 Mar;41(3):195-206.

3. Chanavaz M. Patient screening and medical evaluation for implant and preprosthetic surgery. J Oral Implantol. 1998;24(4):222-9.

4. Carinci F, Lauritano D, Bignozzi CA, et al. A New Strategy Against Peri-Implantitis: Antibacterial Internal Coating. Int J Mol Sci. 2019;20(16):3897.

5. Luo Q, Ding Q, Zhang L, Xie QF. Quantitative analysis of occlusal changes in posterior partial fixed implant supported prostheses. Beijing Da Xue Xue Bao Yi Xue Ban. 2019 Dec 18;51(6):1119-1123.

6. Flieger R, Gedrange T, Grzech-Leśniak K, Dominiak M, Matys J. Low-Level Laser Therapy with a $635 \mathrm{~nm}$ Diode Laser Affects Orthodontic Mini-Implants Stability: A Randomized Clinical Split-Mouth Trial. J Clin Med. 2019;9(1):112.

7. Sorsa T, Alassiri S, Grigoriadis A, et al. Active MMP-8 (aMMP-8) as a Grading and Staging Biomarker in the Periodontitis Classification. Diagnostics (Basel). 2020;10(2):61.

8. Gjerde CG, Shanbhag S, Neppelberg E, Mustafa K, Gjengedal H. Patient experience following iliac crest-derived alveolar bone grafting and implant placement. Int J Implant Dent. 2020;6(1):4 . Published 2020 Feb 5.

9. Chaushu L, Chaushu G, Better $\mathrm{H}$, et al. Sinus Augmentation with Simultaneous, Non-Submerged, Implant Placement Using a Minimally Invasive Hydraulic Technique. Medicina (Kaunas). 2020;56(2):75.

10. Pilliar RM. Overview of surface variability of metallic endosseous dental implants: Textured and porous surface-structured designs. Implant Dentistry. 1998;7:305-314. slab prognostic. Adițile osoase au fost corelate cu o rată mai mare de eșec $(55,81 \%$ dintre cazuri). Implanturile inserate la $10^{\circ}$ au avut cea mai bună rată de supraviețuire, iar cele inserate la $35^{\circ}$ şi $55^{\circ}$ au aavut cea mai redusă rată de supraviețuire.

\section{Notă}

Toţi autorii au avut o contribuţie egală la publicarea acestui material.

Conflict of interest: none declared Financial support: none declared

11. Alghamdi HS, Jansen JA. The development and future of dental implants. Dent Mater J. 2020;39(2):167-172.

12. Wu AY, Hsu JT, Fuh LJ, Huang HL. Biomechanical effect of implant design on four implants supporting mandibular full-arch fixed dentures: In vitro test and finite element analysis. J Formos Med Assoc. 2019;:S0929-6646(19)30872-1.

13. Kang DW, Yun PY, Choi YH, Kim YK. Sinus bone graft and simultaneous vertical ridge augmentation: case series study. Maxillofac Plast Reconstr Surg. 2019;41(1):36.

14. Scarano A, Lorusso F, Santos de Oliveira P, Kunjalukkal Padmanabhan S, Licciulli A. Hydroxyapatite Block Produced by Sponge Replica Method: Mechanical, Clinical and Histologic Observations. Materials (Basel). 2019;12(19):3079.

15. Joshi CP, D'Lima CB, Karde PA, Mamajiwala AS. Ridge augmentation using sticky bone: A combination of human tooth allograft and autologous fibrin glue. J Indian Soc Periodontol. 2019;23(5):493-496.

16. Liu Y, Sun X, Yu J, et al. Platelet-Rich Fibrin as a Bone Graft Material in Oral and Maxillofacial Bone Regeneration: Classification and Summary for Better Application. Biomed Res Int. 2019;2019:3295756.

17. Song SY, Kang KH, Lee JY, Shin SW. Effects of type of magnet attachment and implant angulation in two implant overdenture models. J Adv Prosthodont. 2020;12(1):33-37.

18. Sigcho López DA, Pintaudi Amorim K, Laganá DC. Auxiliary Reflectance Sensor for Guided Surgery with Dental Implants: In Vitro Study. Eur J Dent. 2020;14(1):115-122. 